\title{
The Growth of Nd:YAG Single Crystals by Czochralski Method with ADC-CGS - Preliminary Work
}

\author{
Wan Hairul Anuar Kamaruddin (Corresponding author) \\ Physics Department, Faculty of Science \\ Universiti Teknologi Malaysia \\ 81310 UTM Skudai, Johor, Malaysia \\ Tel.607-553-4204Ｅ-mail: whanuar@utm.my
}

\author{
Hamdan Hadi Kusuma, Tan Hang Khume, Mohd Hani Adam, Md Supar Rohani \& Md Rahim Sahar \\ Physics Department, Faculty of Science, Universiti Teknologi Malaysia \\ 81310 UTM Skudai, Johor, Malaysia
}

The research is financed by Ministry of Science, Technology and Innovation under vote UTM 74529.

\begin{abstract}
Although Nd:YAG was invented in the 1960s in the last century, it has been and still the most commonly crystal material widely used in all types of solid-state lasers systems such as frequency-doubled continuous wave, high-energy Q-switched, and so forth in applications to the medical, industrial, military and scientific research. A Crystal Growth System namely Automatic Diameter Control - Crystal Growth System (ADC-CGS) was utilized to prepare a single crystal of Nd:YAG grown in the $<111>$ direction using the Czochralski. By an effective control on the growth parameter such as maintaining temperature gradient by controlling the output power and the growth rate, an Nd:YAG single crystal with the dimensions of $75 \mathrm{~mm}$ in length and $30 \mathrm{~mm}$ in diameter was successfully produced using the ADC-CGS. The color of the Nd:YAG single crystal is slightly purple when exposed to the light. This is a unique characteristic of YAG crystal when doped with Neodymium (Nd) followed by a better fluorescence lifetime and thermal conductivity.
\end{abstract}

Keywords: Czochralski method, Nd:YAG, Crystal growth, Oxide crystal

\section{Introduction}

Crystal growth involves a variety of research fields ranging from surface physics, crystallography, and material sciences to condenser mater physics. Even though it has been studied extensively more than 100 years, crystal growth still plays an important role in both theoretical and experimental research fields, as well as in applications (Z.Zhang, 1999). Nowadays, crystals are produced artificially to satisfy the needs of science, technology and jewellery. The ability to grow high quality crystals has become an essential criterium for the competitiveness of nations (H. Wenzl and H. Schlich, 2006).

Until now, neodymium: yttrium aluminium garnet (Nd:YAG) laser rods have been the highest volume product for most leading manufacturers. In the future, the optical-crystal industry will deliver tens of millions of crystal parts annually [J. Nicholls, 2001]. Nd:YAG crystals is ordinarily produced with concentrations from $0.18 \%$ to $1.1 \%$ for applications in all types of solid-state lasers systems-frequency-doubled continuous wave, high-energy Q-switched, military, industrial, medical and scientific markets (E. Kanchanavaleerat et. al, 2004). The Czochralski technique (M. T. Santos et. al, 1994; E.Talik, 2007; N.V.D. Bogaert and F. Dupret, 1997], also known as crystal pulling, is widely known for growing single crystals from the melt and has become the method of choice for the growth and production of many bulk oxide materials (C.D. Brandle, 2004).

In the present work, the reports is on the results obtained during the first trial of growing Nd:YAG single crystal by Czochralski method with ADC-CGS. It will then conclude with outline directions for further research and development.

\section{Experimental}

\subsection{Crystal Growth System}

To grow high quality Nd:YAG single crystal, an automatic diameter control system for Czochralski crystal growth from melt was used. A Crystal Growth System namely Automatic Diameter Control - Crystal Growth 
System (ADC-CGS) from Thermal Technology Inc. is well-equipped with growth system especially the furnace including the insulator and iridium crucible, power supply using radio frequency of $30 \mathrm{kHz}$ with the output power up to $25 \mathrm{~kW}$, pulling device, process controller by using ADC software with Labview, vacuum, water cooling and gas delivery system were utilized. Figure 1 shows a picture of ADC-CGS heating zone.

\subsection{The Growth of Nd:YAG}

The melts were prepared from the oxide powder of high purity $\mathrm{Al}_{2} \mathrm{O}_{3}, \mathrm{Y}_{2} \mathrm{O}_{3}$ and $\mathrm{Nd}_{2} \mathrm{O}_{3}$ and Nd:YAG crystal with the dopant concentration of $\mathrm{Nd}$ about $1.0 \% \mathrm{~atm}$. that bought from China was put into iridium crucible. The iridium crucible size of $30 \mathrm{~mm} \times 30 \mathrm{~mm} \times 1.8 \mathrm{~mm}$ was placed at the center of work coil position and was surrounded with $\mathrm{ZrO}_{2}$ grains. To decrease the radial temperature gradient above the melt surface, the tube $\mathrm{Al}_{2} \mathrm{O}_{3}$ insulator was used to improve the thermal insulations. Because it is necessary to protect crucibles at high temperature and/or control the melt volality, the growth is carried out under argon gases (M. Kokta, 2007). The process is starts from chamber pump down to $1.0 \times 10^{-1}$ torr and then heat up to $2500 \mathrm{mV}$ in 1.0 hour in order to burn off the water vapor in the powder. Then the power was in step decrease to $1000 \mathrm{mV}$ to fill up the argon gas until psig -7 " $\mathrm{Hg}$ and heat up again until the material melt. The material was partially melt approximately at $2950 \mathrm{mV}$, and the power continuously control in order to make sure the melt held at a constant temperature (with a small degree of temperature gradient). Figure 3 shows the heat-up process increases by step until get to the melting point. The temperature of the hot zone was monitored by a pyrometer as a reference.

A seed crystal suspended from a rotating alumina seedholder is then slowly lowered into the furnace cavity, and the tip is touched into the melt. If the melt temperature is in the appropriate range just slightly above the melting point of the material $\left(1970^{\circ} \mathrm{C}\right.$ for $\left.\mathrm{Nd}: \mathrm{YAG}\right)$, growth of a crystal can be initiated by starting to slowly withdraw the seed rod. The Nd:YAG crystal were pulled along the axis perpendicular with $\langle 111\rangle$ oriented seed from the melt start at rate $1.2 \mathrm{~mm} / \mathrm{hr}$ in manual mode. After successful seeding, the crystal diameter is increased from the seed diameter to that of the useful portion of the crystal. The rotation speed was kept constant at $15 \mathrm{rpm}$ during crystal growth process. The desired full diameter was setting to $22 \mathrm{~mm}$. The growing crystals were slowly pulled from the residual melt in automatic mode with some adjustment to the parameter such as pulling rate, rate limit and weight scale factor in order to get the crystal as in the setting parameter condition. Table 1 shows the setting parameter for this Nd:YAG crystal growth. The crucible was not rotated during the growth. After completion of the growth run, the crystal was cooled from $2980 \mathrm{mV}$ to $1500 \mathrm{mV}$ in 6 hours and rotated at a rate of about 10 rpm.

\section{Result and Discussion}

Figure 3 shows the first Nd:YAG crystal grown in this study using ADC-CGS. The crystal is completely transparent. A huge crack was found extends upward from the bottom to the center of the crystal.

The results given by D. E. Eakins et. al (2004), reported that the factors contributing to cracking were identified as hoop stress, which develops due to the difference in cooling rates between the boule surface and core, surface defects such as iridium particles and thermal shock during seeding. That might be happens to this study because the cooling process is just 6 hours and there can be a large of temperature gradient throughout the hot zone. The cause of cracking also might be from the jerk-out process of the crystal from the melt. It was proved from the cracking start from the bottom to upward. As shown in Table 1, the jerk-out process was used a speed of 3600 $\mathrm{mm} / \mathrm{hr}$ and pull out until $12 \mathrm{~mm}$. The high speed of jerk-out process applied to the crystal might begin the crack and add together with the large temperature gradient that expands the cracking.

Refer to the example of the early garnet crystal in Figure 4, it could be say that our first attempt to grow the Nd:YAG crystal is not too bad. Even it is not a perfect crystal in term of the physical and optical qualities but it prove that our ADC-CGS can grow the higher oxide melting.

\section{Further Research and Development}

The next process is to characterize the Nd:YAG crystal such as in terms of identifying the crystal orientation using X-Ray diffractometer, spectroscopy measurement to monitor $\mathrm{Nd}^{3+}$ concentration levels and impurity contents and also to identify the excitation wavelength using a Luminescence Spectrometer.

\section{Conclusion}

In conclusion, a Nd:YAG crystal has been successfully grown by Czochralski method using ADC-CGS. The crystal has a crack starting from the bottom to the center. A large temperature gradient from the shortest time of cooling process and high speed of jerk-out process might be the cause of the cracks. 


\section{References}

C.D. Brandle. (2004). Czochralski growth of oxides. J. Crystal Growth, 264, 593-604.

D. E. Eakins, M. Held, M. G. Norton, D. F. Bahr. (2004). A study of fracture and defects in single crystal YAG. J. Crystal Growth, 267, Issue 3-4, 502-509.

E.Talik. (2007). Ninetieth anniversary of Czochralski method. J. Alloy and Compound, 442, 70-73.

Eunchong Kanchanavaleerat, Didier Cochet-Muchy, Milan Kokta, Jennifer Stone-Sundberg, Paul Sarkies, Julian Sarkies and Jonathan Sarkies. (2004). Crystal Growth of High Doped Nd:YAG. J. Optical Material, 26(4), 337-341.

H. Wenzl, H. Schlich. (2006). Crystal and Crystal Growth: An Introductory Survey For Beginners. [Online] Available: http://www.mateck.com/Intro/spg10e.asp.html, MaTecK GmbH, Germany.

John Nicholls. (2001). Birefringent crystals find new niche in WDM networks. Newsletter CGT, WDM Solutions December.

M. T. Santos, J. C. Rojo, L. Arizmendi, E. Dieguez. (1994). Flat interface in the growth of $\mathrm{LiNbO}_{3}, \mathrm{Bi}_{12} \mathrm{SiO}_{20}$ and $\mathrm{Bi}_{12} \mathrm{GeO}_{20}$ crystals from the melt. J. Crystal Growth, 142(1-2) 103-110.

Milan Kokta. (2007). Growth of Oxide Laser Crystals. J. Optical Material, 30(1), 1-5.

N. Van den Bogaert, F.Dupret. (1997). Dynamic global simulation of the Czochralski process I. Principles of the method. J. Crystal Growth, 171, 65-76.

Z. Zhang. (1999). Crystal Growth, Proceeding of National Academy of Sciences, USA, 96, Issue 20, 11069-11070.

Table 1. Setting Parameter for Nd:YAG Crystal Growth

\begin{tabular}{|l|l|l|l|}
\hline Seed Diameter $(\mathrm{mm})$ & 5 & Cool-down Time $(\mathrm{hr})$ & 6 \\
\hline Full Diameter $(\mathrm{mm})$ & 22 & Max Control Power $(\mathrm{mV})$ & 2700 \\
\hline Shoulder Angle & 22.5 & Rate Limit $(\mathrm{mV} / \mathrm{hr})$ & 2 \\
\hline Pull Speed $(\mathrm{mm} / \mathrm{hr})$ & $0.6-1.2$ & Rotation Rate $(\mathrm{rpm})$ & 15 \\
\hline Neck Length $(\mathrm{mm})$ & 1 & Break Diameter $(\mathrm{mm})$ & 35 \\
\hline Desired Length $(\mathrm{mm})$ & 40 & Break Length $(\mathrm{mm})$ & 60 \\
\hline Weight Scale Factor & 1 & Generator Filter & 0.005 \\
\hline Weight Filter & 0.1 & Jerk-out Speed $(\mathrm{mm} / \mathrm{hr})$ & 3600 \\
\hline Heat-up Time $(\mathrm{hr})$ & 1.5 & Jerk-out Height $(\mathrm{mm})$ & 12 \\
\hline
\end{tabular}

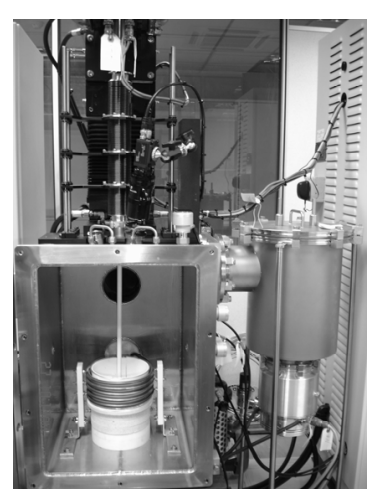

Figure 1. Automatic Diameter Control - Crystal Growth System Heating Zone 


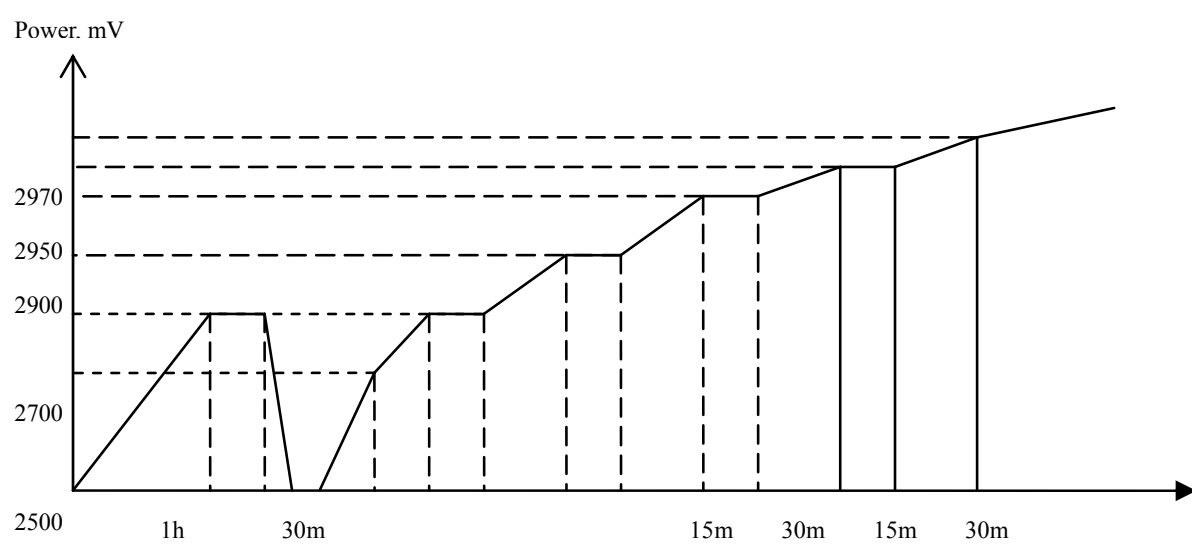

Figure 2. Heat-up process: Output Power vs. Elapsed time.

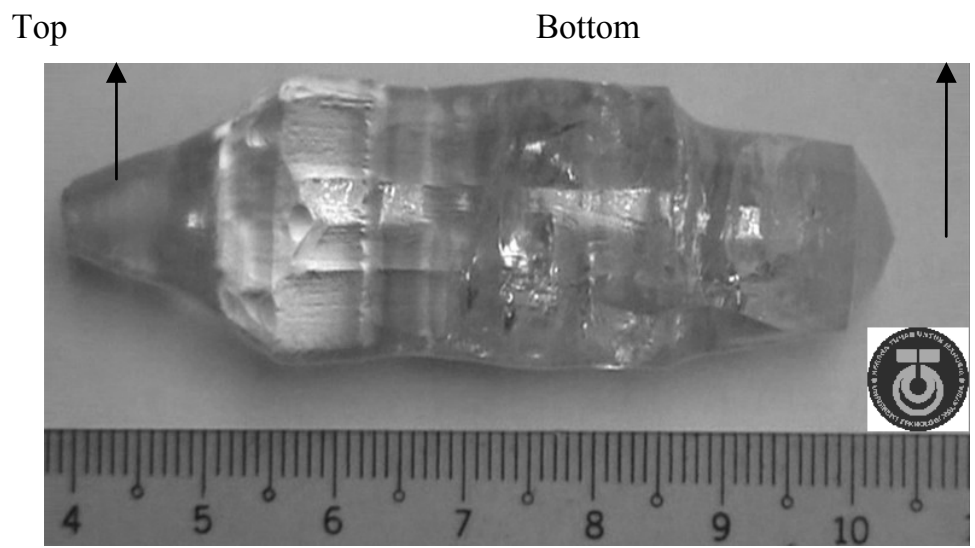

Figure 3. Nd:YAG single crystal with the $<111>$ growth orientation. The weight of the crystal is 68.04 grams. The length is $62 \mathrm{~mm}$ and full diameter reach $22 \mathrm{~mm}$.

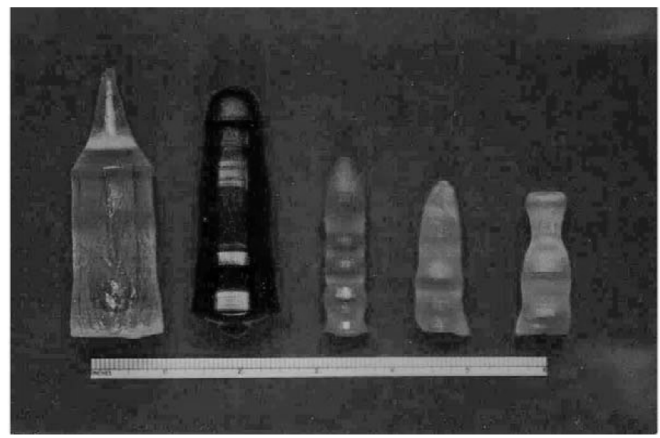

Figure 4. Early garnet crystals grown using RF (C.D. Brandle, 2004). 